\title{
A novel estimate of ocean oxygen utilisation points to a reduced rate of respiration in the ocean interior
}

\author{
O. Duteil ${ }^{1}$, W. Koeve ${ }^{1}$, A. Oschlies ${ }^{1}$, D. Bianchi ${ }^{2}$, E. Galbraith ${ }^{2}$, I. Kriest ${ }^{1}$, and R. Matear ${ }^{3}$ \\ ${ }^{1}$ GEOMAR, Helmholtz Center for Ocean Research Kiel, Düsternbrooker Weg 20, 24103 Kiel, Germany \\ ${ }^{2}$ Department of Earth and Planetary Science, McGill University, Montreal, QC, Canada \\ ${ }^{3}$ CSIRO Marine and Atmosphere Research, Hobart, TAS, Australia
}

Correspondence to: O. Duteil (oduteil@geomar.de) and W. Koeve (wkoeve@geomar.de)

Received: 17 January 2013 - Published in Biogeosciences Discuss.: 8 February 2013

Revised: 27 October 2013 - Accepted: 29 October 2013 - Published: 28 November 2013

\begin{abstract}
The Apparent Oxygen Utilisation (AOU) is a classical measure of the amount of oxygen respired in the ocean's interior. We show that AOU systematically overestimates True Oxygen Utilisation (TOU) in 6 coupled circulationbiogeochemical ocean models. This is due to atmosphereocean oxygen disequilibria in the subduction regions, consistent with previous work. We develop a simple, new, observationally-based approach which we call Evaluated Oxygen Utilisation (EOU). In this approach, we take into account the impact of the upper ocean oxygen disequilibria into the interior, considering that transport takes place predominantly along isopycnal surfaces. The EOU approximates the TOU with less than half of the bias of AOU in all 6 models despite large differences in the physical and biological components of the models. Applying the EOU approach to a global observational dataset yields an oxygen consumption rate $25 \%$ lower than that derived from AOU-based estimates, for a given ventilation rate.
\end{abstract}

\section{Introduction}

Respiration is a key biological process in the ocean, oxygen being the major electron acceptor used by microorganisms for the oxidation of organic matter. Classically, respiration in the interior of the ocean has been quantified by the "Apparent Oxygen Utilisation" (AOU). AOU is a time-integrated measure of the amount of oxygen consumed since a given water parcel has left the ocean surface. In this concept it is assumed that sea-surface oxygen is fully equilibrated with the atmosphere, i.e. the concentrations are equivalent to $100 \%$ oxygen saturation, given temperature and salinity of the water (Weiss, 1970), a reasonable assumption over most of the ocean surface.

However, the majority of the ocean's interior water was last at the surface in the high latitudes where significant areas of the surface water are undersaturated with respect to oxygen (e.g. Gordon and Huber, 1990; Körtzinger et al., 2001; Russell and Dickson, 2003; Körtzinger et al., 2004; Keeling et al., 2010). This is the case particularly during winter when the majority of water mass formation and subduction occurs. Surface-ocean oxygen disequilibrium at the time of water mass formation is caused by a range of physical processes (Ito et al., 2004). These include heat loss and the associated increase in oxygen solubility, the upwelling or entrainment of deep waters low in oxygen, and sea-ice coverage impeding air-sea gas exchange. Deep-water formation is a small-scale process and its direct observations and associated oxygen disequilibria are scarce (Körtzinger et al., 2004). The initial magnitude of oxygen undersaturation of deep-ocean water masses is therefore not well known. So far the best information has been provided by the model study of Ito et al. (2004). Minor surface-ocean supersaturation is observed in the tropics, subtropical gyres and high latitudes in summer, principally due to photosynthesis (Craig et al., 1986), and also by radiative warming below the mixed layer (Dietze and Oschlies, 2005). Waters affected by oxygen supersaturation, however, do not contribute much to the ventilation of the ocean's interior due to their relative low density. As a consequence, winter-time high-latitude oxygen undersaturation is the dominant feature affecting ocean ventilation. 
This results in AOU to overestimate oxygen respiration in the ocean globally.

Despite this well known bias (hence the term apparent), AOU is widely used in biogeochemical studies (e.g. Redfield et al., 1963; Anderson and Sarmiento, 1995; Pahlow and Riebesell, 2000; Feely et al., 2004; Sarmiento and Gruber, 2006; Keeling et al., 2010; Duteil et al., 2012). For example, AOU has been used to estimate the total carbon respired in the ocean interior (Ogura et al., 1970; Doval and Hansell, 2000; Aristegui et al., 2002; Carlson et al., 2010). The observed correlation between the disequilibrium of nitrous oxide, a long-lived natural greenhouse gas, and AOU provides a means to estimate nitrous oxide production as a function of oxygen consumption, even though the exact mechanism of production is not resolved (Najjar, 1992; Nevison et al., 2003). Further it has been suggested that AOU has increased in parts of the ocean during the recent decades due to a complex interplay of changes in carbon export and circulation (Emerson et al, 2004). Finally, nutrients may be partitioned into a regenerated and preformed pool using the AOU metric (Ito and Follows, 2005; Duteil et al., 2012) supporting, for example, the distinction of different water masses in the interior of the ocean (Broecker et al., 1985) as well as the analysis of biogeochemical models. For the latter aspect, the ratio of regenerated and total nutrients has been used to characterise the relative strength of biological and physical pathways in the return of nutrients to the ocean's interior (Ito and Follows, 2005).

In this study, we follow three objectives. First, we assess the extent of oxygen disequilibria in six ocean biogeochemical models under steady-state conditions, extending the onemodel work of Ito et al. (2004). Secondly, we develop a new diagnostic aiming at correcting the bias in AOU estimates described above. We refer to this diagnostic as "Evaluated Oxygen Utilisation" (EOU). EOU is based on the assumption of an isopycnal propagation of the surface ocean oxygen disequilibrium into the interior of the ocean. We explore the validity of this new approach using our ensemble of six different coupled biogeochemical/physical models. In these models, the oxygen respired since the water's last contact with the atmosphere ("True Oxygen Utilisation", TOU) is computed explicitly using an idealised passive tracer of preformed oxygen (Ito et al., 2004). Having gained confidence in the validity of the new method, we finally compute AOU and EOU diagnostics from a global observational dataset, allowing the concentrations of regenerated and preformed phosphate to be determined.

\section{Methods}

\subsection{Oxygen utilisation}

Oxygen Utilisation (OU) is generally defined as the difference between the so called "preformed" oxygen and the ac- tual oxygen concentration observed at a given point in the interior of the ocean, i.e. $\mathrm{OU}=\mathrm{O}_{2}$ pre $-\mathrm{O}_{2}$ obs. Preformed oxygen is the oxygen concentration of a water parcel at the time of its last contact with the atmosphere, just before subducted into the ocean interior. Preformed oxygen, however, is not known a priori and cannot be directly measured away from the ocean's surface. In this study the preformed oxygen concentration is estimated in three different ways, leading to three different formulations of oxygen utilisation:

- Apparent Oxygen Utilisation (AOU). AOU assumes that preformed oxygen corresponds to the oxygen saturation concentration, $\mathrm{O}_{2}$ sat, accounting for the insitu potential temperature and salinity. An implicit assumption is that waters are fully equilibrated in regions where subduction occurs.

- True Oxygen Utilisation (TOU). In numerical models, the preformed oxygen concentration can be traced explicitly using an idealised preformed-oxygen tracer. During every model time step, the preformed tracer is restored to the model's simulated oxygen concentration at the sea surface. In the interior of the ocean this preformed oxygen tracer is passively transported by advection and diffusion, with no sinks or sources affecting its concentration. Subtracting the actual oxygen concentration from the preformed oxygen tracer yields TOU (Ito et al., 2004).

- Evaluated Oxygen Utilisation (EOU). In this novel diagnostic, we correct for deviations from complete oxygen saturation in subduction regions in a pragmatic way which can be straightforwardly applied to any model output or to compilations of oxygen measurements. Considering that transport in the ocean takes place predominantly along isopycnal surfaces, we estimate preformed oxygen for each isopycnal layer from the area-weighted annual-mean oxygen disequilibrium below the mixed layer at $50 \mathrm{~m}$ water depth.

The following procedure is applied to each of the 6 models and finally to an observational dataset: we discretisize the ocean into 10 density layers. Pragmatically, we select the $50 \mathrm{~m}$-depth horizon as the outcrop surface in our yearly averaged model outputs and observational dataset. For each density layer, we quantify the mean degree of oxygen saturation (percent) as the area-weighted, horizontally averaged oxygen saturation at the intercept of the isopycnal and the outcrop surface. Everywhere on the isopycnal we compute $\mathrm{O}_{2}$ sat, the oxygen concentration $\left(\mathrm{mmolm}^{-3}\right)$ equivalent to 100 percent saturation, given local potential temperature and salinity (Weiss, 1970). Local preformed oxygen concentration $\mathrm{O}_{2}$ pre is inferred by multiplying local $\mathrm{O}_{2}$ sat with the mean degree of oxygen saturation (as defined above), for that isopycnal. Consequently the mean degree of oxygen saturation 
(percent) is constant on a given isopycnal while the preformed oxygen concentration may vary along the isopycnal due to the mixing of end members differing in preformed oxygen contents. This procedure is repeated for all density layers and EOU is ultimately determined for every grid box as $\mathrm{O}_{2}$ pre minus $\mathrm{O}_{2}$ obs. Our choice of model parameters like the number of density layers or the depths of the intercept horizon is discussed in Sect. 3.5.

The oxygen content of a water mass obtained by mixing two saturated water masses of the same density but with different temperatures, is higher than the oxygen saturation of the resulting water mass, ultimately leading to an apparent increase of the degree of oxygen saturation. This nonlinearity will result in an underestimation of oxygen utilisation in both the AOU or EOU diagnostic. This bias is, however, small and does not exceed a few percent in the ocean interior (Dietze and Oschlies, 2005).

\subsection{Models and datasets}

Six global biogeochemical-circulation models are used in this study (see Table 1 for details): MOM P2A (Gnanadesikan et al., 2004), CSIRO (Matear and Hirst, 2003), om1p7-BLINGv0 (Galbraith et al., 2010), UVIC2.8 (Oschlies et al., 2008), TMM-MIT2.8 (Kriest et al., 2010) and TMM-ECCO2. The TMM-ECCO2 version applies the biogeochemistry of TMM-MIT2.8 (Kriest et al., 2010) but differs by its forcing circulation field. The transport matrix used in the TMM-ECCO2 (Khatiwala, 2007) run has been extracted from the MIT-ECCO2 data assimilation experiment (Stammer et al., 2004). All models are forced by prescribed atmospheric conditions in an attempt to obtain realistic preindustrial circulation fields.

The biogeochemical models range from relatively simple nutrient-restoring type (CSIRO, MOM P2A) to intermediate complexity nutrient-phytoplankton-zooplankton-detritus (NPZD) models (om1p7-BLINGv0, UVIC2.8, MIT2.8, ECCO2). All models include an explicit preformed-oxygen tracer allowing the computation of the True Oxygen Utilisation. Integration time is at least $5000 \mathrm{yr}$ to reach a steadystate quasi-equilibrium. The models do not display significant drifts.

Annual mean outputs from these models are compared with objectively analysed annual means of the World Ocean Atlas (WOA) 2009 (Garcia et al., 2010). Prior to analysis, all model output fields were re-gridded onto the 33 levels $1 \times 1^{\circ}$ WOA grid.

\section{Comparisons of AOU, EOU and TOU}

\subsection{AOU patterns in observations and models}

Patterns of AOU are often used to characterise the main water masses in the global ocean. In the observations (Fig. 1a), the northern deep Atlantic Ocean AOU has low values (below $100 \mathrm{mmol} \mathrm{m}^{-3}$ ), because this region is filled with recently formed, young, North Atlantic Deep Water (NADW). As the NADW spreads southward, it mixes with the older Antarctic Bottom Water (AABW) originating from the Southern Ocean, increasing AOU to values of $120-160 \mathrm{mmolm}^{-3}$. The deep Pacific Ocean is filled by a mixture of AABW and NADW. AOU tends to increase northwards as waters age and lose oxygen by the remineralization of organic matter. In both Atlantic and Pacific oceans, intermediate-depth waters have the highest values of AOU, thought to reflect the depth function of the remineralization of organic matter exported from the surface, combined with long subsurface residence times, especially in the case of oxygen minimum zones. AOU reaches $200 \mathrm{mmol} \mathrm{m}^{-3}$ between $200-1000 \mathrm{~m}$ in the tropical Atlantic Ocean and more than $280 \mathrm{mmol} \mathrm{m}^{-3}$ between 200 $2000 \mathrm{~m}$ in the tropical and North Pacific Ocean.

All six models studied here yield global patterns of AOU which are similar to observations (Fig. 1b): low values in the NADW (below $100 \mathrm{mmolm}^{-3}$ ), intermediate AOU in the AABW (between 100 to $150 \mathrm{mmol} \mathrm{m}^{-3}$ ), high values in tropical regions, and a northward increase of AOU in the Pacific Ocean to values higher than $200 \mathrm{mmolm}^{-3}$. This suggests that the models used in this study, to first order, represent the combined effects of circulation and biology realistically and are therefore suitable for investigating the large-scale patterns of oxygen utilisation in the ocean.

However, some regional differences exist between models and observations. The most striking difference occurs in the tropical and north Pacific Ocean. In MOM P2A and MIT28, AOU is significantly lower than in the WOA (220$240 \mathrm{mmolm}^{-3}$ ), whereas the volume of high-AOU water (greater than $280 \mathrm{mmolm}^{-3}$ ) is larger in om1p7-BLING than in WOA. The other models (CSIRO, UVIC and ECCO2) show intermediate values. These differences may be due to a variety of processes, including inter-model differences of oxygen disequilibrium at the outcrops, model circulation (i.e. water mass ages), export patterns, and organic-matter remineralization length scales implemented in the individual models. Disentangling these processes would require a suite of sensitivity experiments for each model with additional tracers (e.g. ideal age) and is outside the scope of this work. Instead, we take advantage of an ensemble of models which collectively encompass the observed features but display significant difference to allow a reasonable test of the robustness of our approach. 
Table 1. Main characteristics of the models analysed in this study.

\begin{tabular}{|c|c|c|c|c|c|c|}
\hline Model & MOM-P2A & CSIRO & $\begin{array}{l}\text { om1p7- } \\
\text { BLINGv0 }\end{array}$ & UVIC & $\begin{array}{l}\text { TMM- } \\
\text { MIT28 }\end{array}$ & $\begin{array}{l}\text { TMM- } \\
\text { ECCO2 }\end{array}$ \\
\hline Resolution & $3.75 \times 4$ & $3.2 \times 5.6$ & $\begin{array}{l}0.6 \text { (eq) to } \\
2 \times 3\end{array}$ & $3.6 \times 3.6$ & $2.8 \times 2.8$ & $1 \times 1$ \\
\hline $\begin{array}{l}\text { Vertical } \\
\text { levels }\end{array}$ & 24 & 21 & 28 & 19 & 15 & 23 \\
\hline $\begin{array}{l}\text { Integration } \\
\text { type }\end{array}$ & online & online & online & online & offline & offline \\
\hline $\begin{array}{l}\text { Wind } \\
\text { stress }\end{array}$ & ECMWF & $\begin{array}{l}\text { Previous } \\
\text { coupled exp. }\end{array}$ & CORE & $\begin{array}{l}\text { NCEP- } \\
\text { NCAR }\end{array}$ & $\begin{array}{l}\text { NCEP- } \\
\text { NCAR }\end{array}$ & CORE \\
\hline Biology & OCMIP(N) & $\mathrm{N}$ & $\mathrm{N}$ & NPZD & NPZD & NPZD \\
\hline Boxes & $\begin{array}{l}4 \\
\mathrm{PO}_{4}, \\
\text { (implicit PZD), } \\
\mathrm{O}_{2}, \\
\text { DIC, TALK }\end{array}$ & $\begin{array}{l}4 \\
\mathrm{PO}_{4}, \\
\text { (implicit PZD), } \\
\mathrm{O}_{2}, \\
\text { DIC, TALK }\end{array}$ & $\begin{array}{l}4 \\
\mathrm{PO}_{4}, \\
\text { (implicit PZD), } \\
\mathrm{O}_{2}, \\
\text { DOP, iron }\end{array}$ & $\begin{array}{l}9 \\
2 \text { phy., } 1 \text { zoo., } \\
\mathrm{NO}_{3}, \mathrm{PO}_{4}, \\
\text { Detritus, } \\
\mathrm{O}_{2}, \\
\text { DIC, TALK }\end{array}$ & $\begin{array}{l}6 \\
1 \text { phy., } 1 \text { zoo., } \\
\mathrm{PO}_{4}, \\
\text { DOP, DOM, } \\
\mathrm{O}_{2}\end{array}$ & $\begin{array}{l}6 \\
1 \text { phy., } 1 \text { zoo., } \\
\mathrm{PO}_{4}, \\
\text { DOP, DOM, } \\
\mathrm{O}_{2}\end{array}$ \\
\hline
\end{tabular}

\subsection{Upper ocean oxygen disequilibrium}

To evaluate the validity of the AOU approximation, in particular the assumption that the subducted water is fully equilibrated with atmospheric oxygen, we computed the oxygen disequilibrium near surface in the observations and models. The most significant atmosphere/upper ocean oxygen disequilibrium occurs in the high latitude subduction regions, where deep water (considered here as the water denser than $1027.5 \mathrm{~kg} \mathrm{~m}^{-3}$ ) forms. Such deep water is subducted both in the Southern Ocean (Antarctic Bottom Water: AABW) and in the northern North Atlantic (NADW: North Atlantic Deep Water) (Fig. 2a).

In the observations, the annual mean oxygen field of waters denser than $1027.5 \mathrm{~kg} \mathrm{~m}^{-3}$ at $50 \mathrm{~m}$ depth around Antarctica is significantly undersaturated (mean saturation rate of 86 percent), particularly in the Ross and Wedell Sea (Gordon and Huber, 1990; Keeling et al., 2010). The north Atlantic regional annual mean oxygen saturation at $50 \mathrm{~m}$ depth is higher and close to saturation ( 90 percent or more, Fig. 2b)

In the models studied here, the degree of saturation at the outcrop of NADW is high and above 90 percent, consistent with observations. Concerning the Southern Ocean, the models can be classified in two groups. In MOM P2A, MIT28 and ECCO2, Southern Ocean waters are well oxygenated at $50 \mathrm{~m}$ depth (mean saturation degree higher than $90 \%$ ), while in CSIRO, om1p7-BLINGv0 and UVIC the mean oxygen saturation degree is low, between 75 and 85 percent. In comparison, the observations suggest saturation levels of about 85 percent in the outcrop region.
A possible cause of the differences between models is linked to the intensity of diapycnal mixing in the ocean's interior, which controls the overturning strength, and consequently the subduction rate (Gnanadesikan, 1999). However, high mixing intensity implies a strong overturning and a high subduction rate, but at the same time a stronger impact of deoxygenated deep water on ocean-surface oxygen conditions. Inter-model differences in ice coverage may also be significant.

Again, the diversity of model behaviour provides a range of scenarios to test the robustness of the EOU concept. Disentangling the mechanisms which lead to near-surface disequilibria of oxygen in the different models would need several sensitivity experiments, similar to those carried out by Ito et al. (2004), but for each of the models. This is beyond the scope of this study. In the following section, we evaluate the impact of the significant oxygen disequilibrium in the upper ocean on the evaluation of the oxygen utilisation in more detail.

\subsection{Evaluation of the AOU approach in models}

Comparing AOU with TOU reveals that AOU substantially and systematically overestimates TOU in all six models (Fig. 3a), because surface waters are not fully saturated prior to subduction into the ocean's interior (see Sect. 3.2). Surface oxygen disequilibria modify the amount of preformed oxygen, $\mathrm{O}_{2}$ pre, transferred into the ocean's interior by transport along isopycnals. Because $\mathrm{O}_{2}$ pre is smaller than $\mathrm{O}_{2}$ sat in most of the ocean's interior, TOU is less than AOU and the AOU-TOU difference is positive. Slightly nega- 

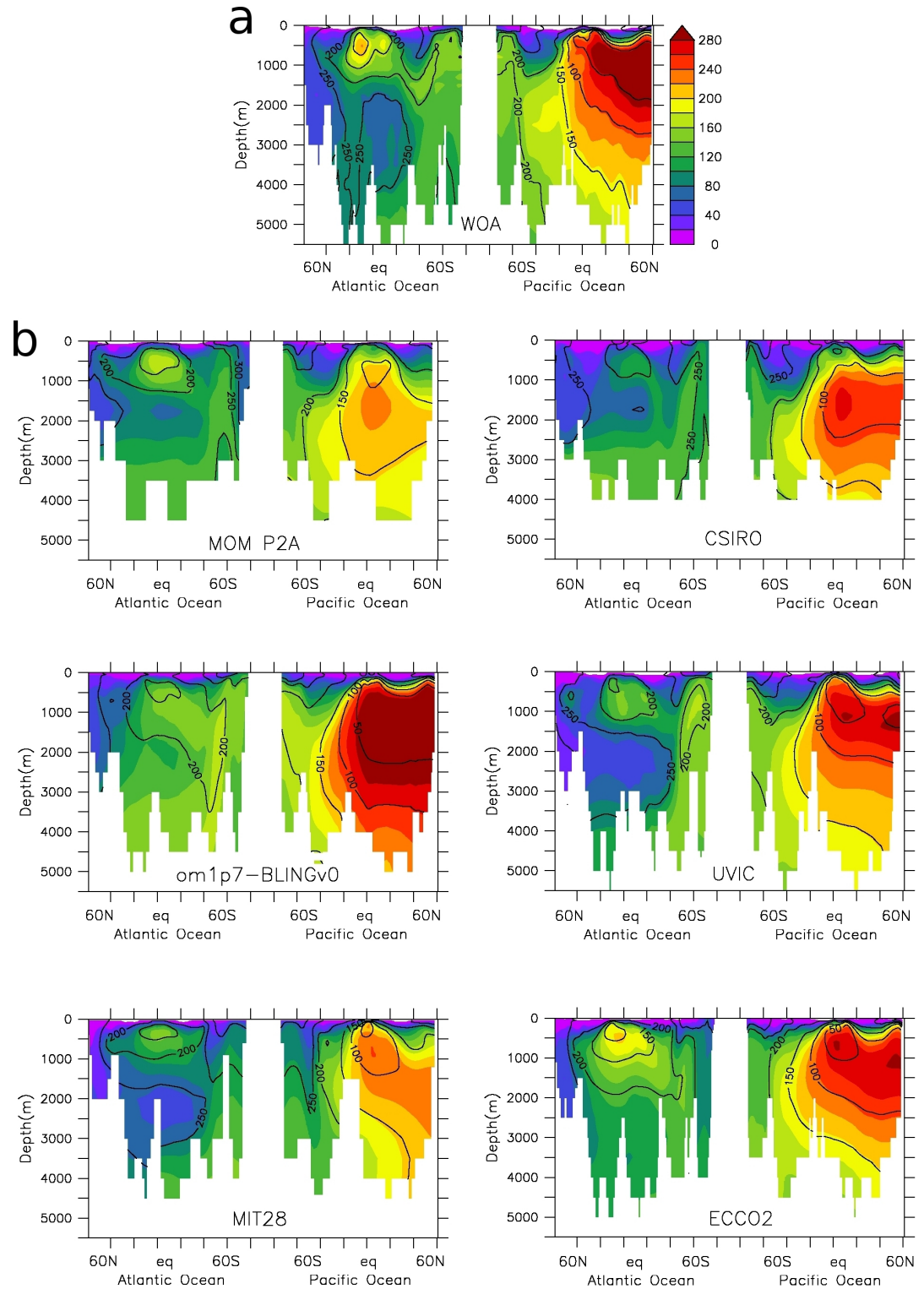

Fig. 1. Apparent Oxygen Utilisation (AOU) $\left(\mathrm{mmolm}^{-3}\right)$ along an Atlantic Ocean meridional section $\left(30^{\circ} \mathrm{W}\right)$ and a Pacific Ocean meridional section $\left(150^{\circ} \mathrm{W}\right)$ in the WOA dataset (a) and in the model outputs (b): MOM-P2A, CSIRO, om1p7-BLINGv0, UVIC, TMM-MIT28, TMMECCO2. Contour lines refer to oxygen concentrations $\left(\mathrm{mmolm}^{-3}\right)$.

tive values (between -1 and $-5 \mathrm{mmolm}^{-3}$ ) of AOU-TOU are only observed in tropical-subtropical waters of the upper thermocline of some of the models. This may be due to subduction of slightly oversaturated waters at the lowlatitude outcrops of these density layers or to the nonlinear effect of mixing waters equilibrated at different temperatures but identical densities.

Maximum AOU-TOU differences along the transects investigated in Fig. 3. range from 23 (MIT2.8) to $117 \mathrm{mmol} \mathrm{m}^{-3}$ (om1p7-BLINGv0) (CSIRO: $31 \mathrm{mmol} \mathrm{m}^{-3}$, MOM P2A: $61 \mathrm{mmolm}^{-3}$, ECCO2: $70 \mathrm{mmolm}^{-3}$, UVIC: $76 \mathrm{mmol} \mathrm{m}^{-3}$ ). In their model study of oxygen utilisa- tion, Ito et al. (2004) found a maximum oxygen disequilibrium of $73 \mathrm{mmolm}^{-3}$. These authors observed a maximum oxygen disequilibrium in the Southern Ocean (at least $50 \mathrm{mmolm}^{-3}$ south of $60 \mathrm{~S}$ ) and in ocean bottom waters (at least $30 \mathrm{mmol} \mathrm{m}^{-3}$ deeper than $2500 \mathrm{~m}$ ). The location of their maximum disequilibrium is consistent with the results of our study.

\subsection{Evaluation of the EOU approach in models}

The large AOU-TOU differences simulated by all our models highlights the uncertainty in using AOU to quantify oxygen utilisation in the real ocean. In order to better estimate 

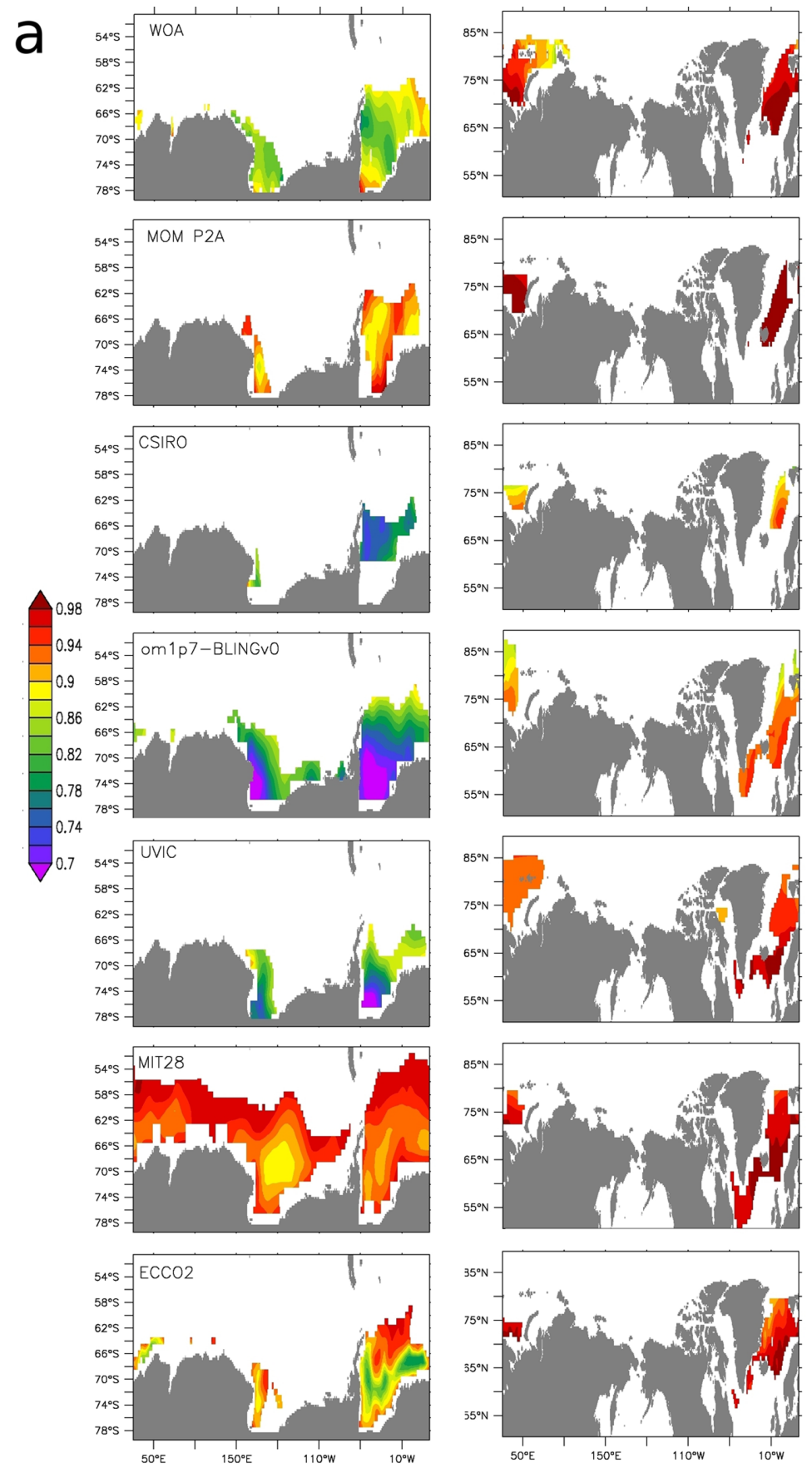

b
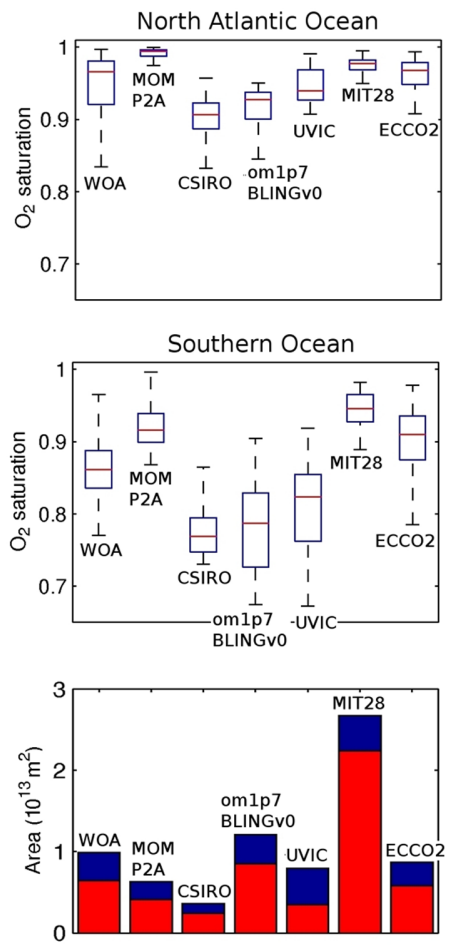

Fig. 2. (a) Distribution of oxygen saturation at $50 \mathrm{~m}$ depth in the southern (left) and northern (right) outcrop regions of water masses denser than $1027.5 \mathrm{~kg} \mathrm{~m}^{-3}$. (b) Box plot of volume weighted oxygen saturation in the Northern (top panel) and Southern (middle panel) Hemispheres, respectively, at $50 \mathrm{~m}$ depth and where the density is greater than $1027.5 \mathrm{~kg} \mathrm{~m}^{-3}$. The lower panel shows the area in the Northern (blue) and Southern (red) Hemisphere where the density is greater than $1027.5 \mathrm{~kg} \mathrm{~m}^{-3}$.

oxygen utilisation in the ocean, we present the EOU diagnostic. The ability to estimate the oxygen utilisation at the global or basin scale is assessed by computing for each model the volume-weighted Root-Mean-Square (RMS) error for the
AOU and EOU relative to the TOU.

$$
\operatorname{RMSErr}_{X}=\sqrt{\sum_{i} \sum_{j} \sum_{k}\left((X-\mathrm{TOU})^{2} \times \frac{V_{i, j, k}}{V_{\text {ocean }}}\right)}
$$



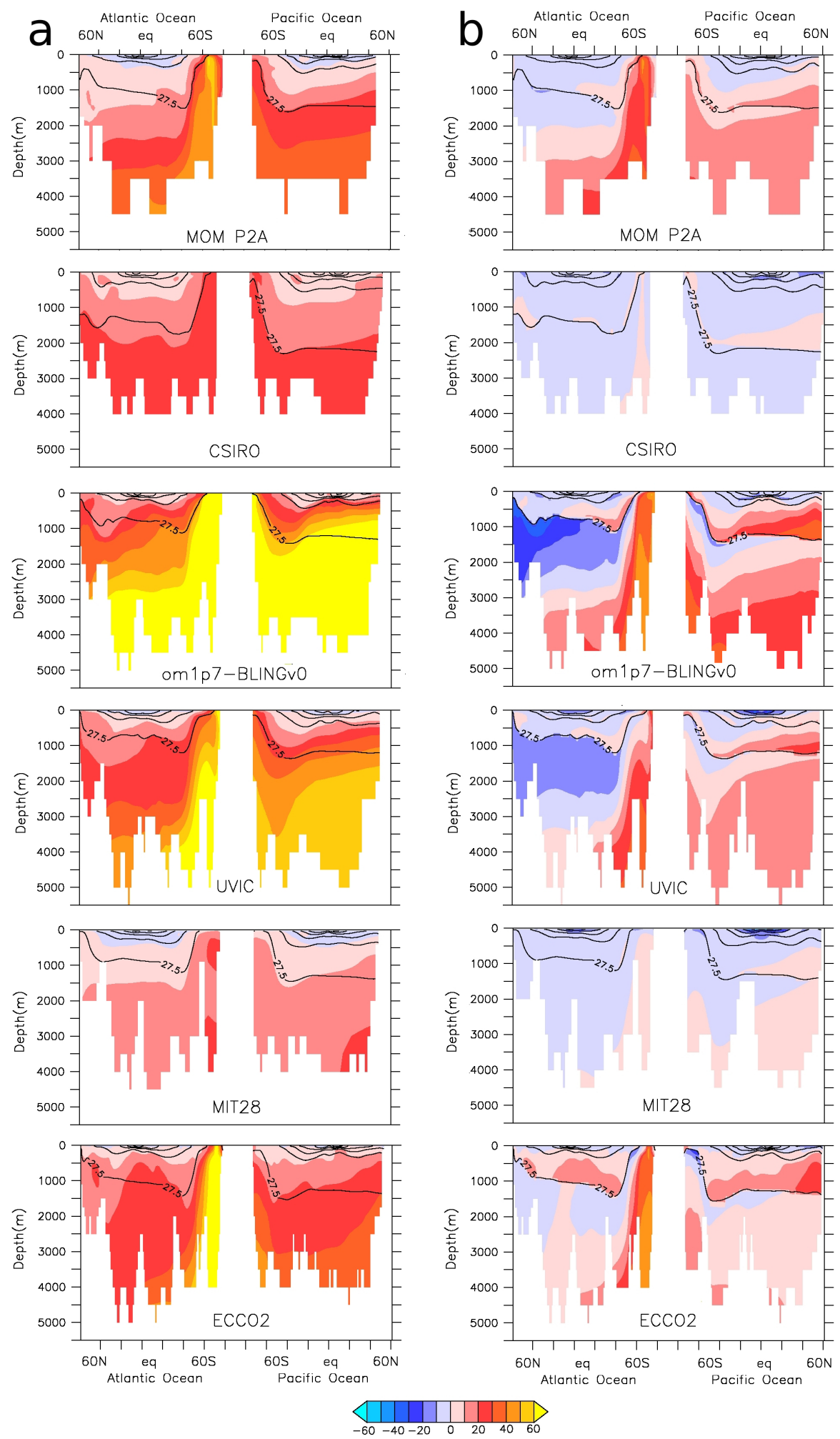

Fig. 3. (a) Apparent Oxygen Utilisation (AOU) - True Oxygen Utilisation (TOU) $\left(\mathrm{mmol} \mathrm{m}^{-3}\right)$ and (b) evaluated Oxygen Utilisation (EOU) - True Oxygen Utilisation (TOU) $\left(\mathrm{mmolm}^{-3}\right)$ along an Atlantic meridional section $\left(30^{\circ} \mathrm{W}\right)$ and Pacific meridional section $\left(150^{\circ} \mathrm{W}\right)$ in different models: CSIRO, MOM-P2A, om1p7-BLINGv0, UVIC, TMM-MIT28, TMM-ECCO2. Levels of constant density are traced in contour. 

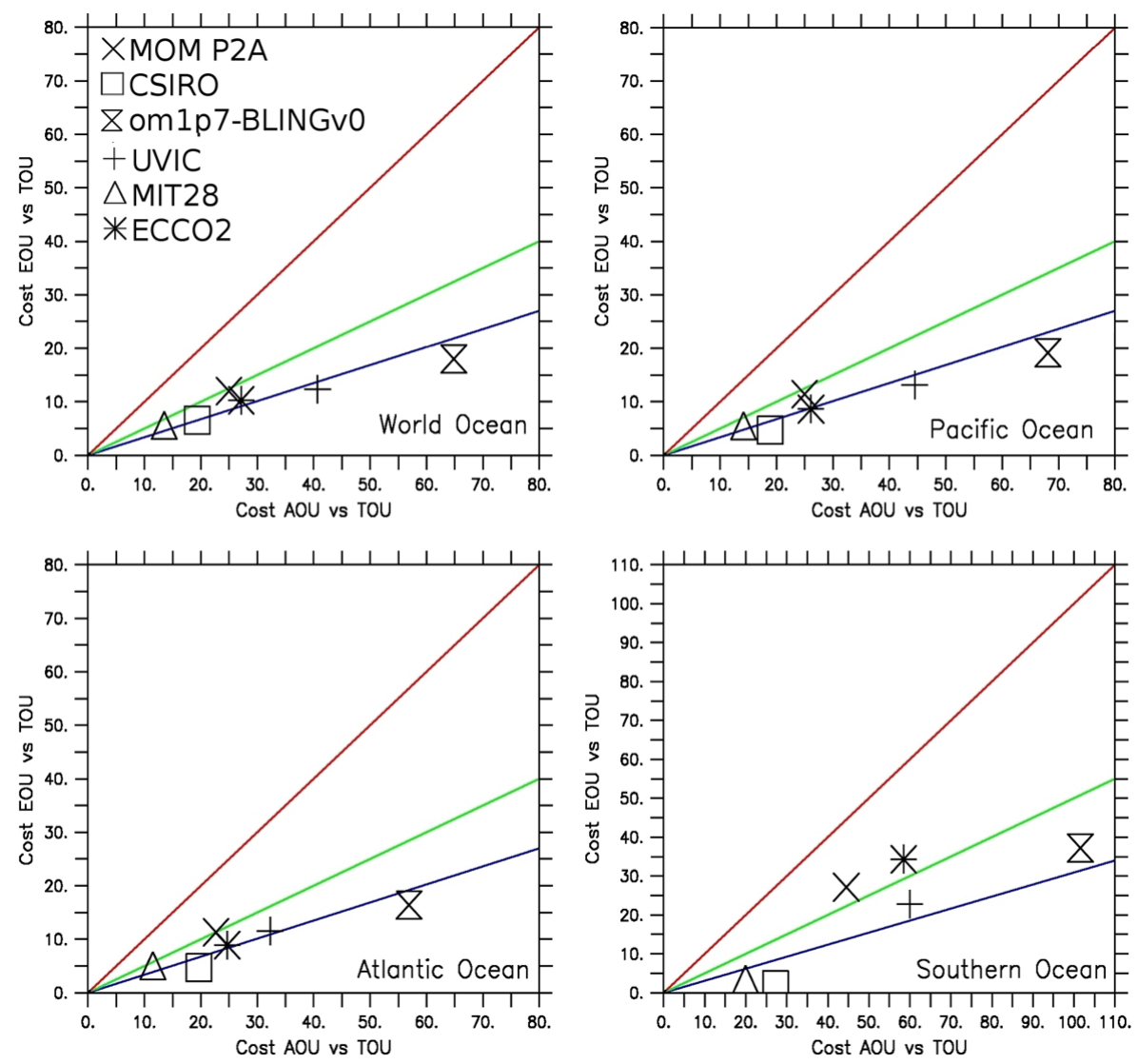

Fig. 4. RMS errors for AOU vs. TOU (abscissae) and EOU vs. TOU (ordinates) for the global ocean, Pacific, Atlantic and Southern Ocean. The red line is the $1: 1$ line, indicating that the performance of EOU and AOU to estimate TOU is equivalent. The green and blue lines represent the 2:1 and 3:1 lines, respectively. (EOU estimates TOU "twice better" and "three times better" than AOU). EOU has been computed using 10 isopycnal layers.

where $X$ is either AOU or EOU and $i, j, k$ denote the dimensions of space. The sums of the squared differences are weighted by the relative volume $V$ of the corresponding grid boxes over the total ocean volume.

The computed RMS error is less than half when EOU is used instead of AOU (Fig. 4) to estimate TOU. This reduction of RMS error holds for all ocean basins. Regional differences between EOU and TOU are shown in Fig. $3 \mathrm{~b}$. In the case of CSIRO and MIT28, EOU is a very good proxy of the TOU, with the maximum difference of less than $10 \mathrm{mmol} \mathrm{m}^{-3}$. In MOM P2A, UVIC and ECCO2, EOU represents well TOU in the Atlantic and Pacific basins, with a maximum difference of less than $20 \mathrm{mmolm}^{-3}$. This difference is higher in om1p7-BLINGv0, with values up to $50 \mathrm{mmol} \mathrm{m}^{-3}$ in the deep Pacific Ocean. However, even with this model the bias of EOU is only about half that of AOU (Fig. 3a). In UVIC and om1p7-BLINGv0, EOU underestimates (i.e. negative EOU-TOU values) oxygen utilisation by $10-20 \mathrm{mmol} \mathrm{m}^{-3}$ (UVIC) and $10-40 \mathrm{mmolm}^{-3}$ (om1 7 BLINGv0) at intermediate depths (1000-2000 m) in the Atlantic Ocean.

\subsection{Uncertainties of the EOU approach}

The EOU approach we suggest here is an ad hoc approximation of true oxygen utilisation in the ocean designed to be applicable to both model outputs and observations. As such, the estimate of preformed oxygen in the EOU approach neglects some processes actually taking place in the ocean. In particular, we assumed that the water is, in the ocean interior, transported along isopycnals exclusively and hence neglected diapycnal mixing. In the following, we discuss and evaluate critical parameters of the EOU approach. In particular we discuss the consequences of our area-weighting of surface oxygen disequilibria, the use of annual vs. winter-time data, the number of density layers and the depth of the intercept horizon.

In the EOU approach, the mean oxygen saturation of each of the considered isopycnal layers is estimated by computing the area-weighted mean oxygen concentration at the intercept of this layer with the $50 \mathrm{~m}$ depth horizon. This is an approximation since in reality waters in the interior of the ocean are variable mixtures of water masses formed in different source regions and having different specific surface oxy- 

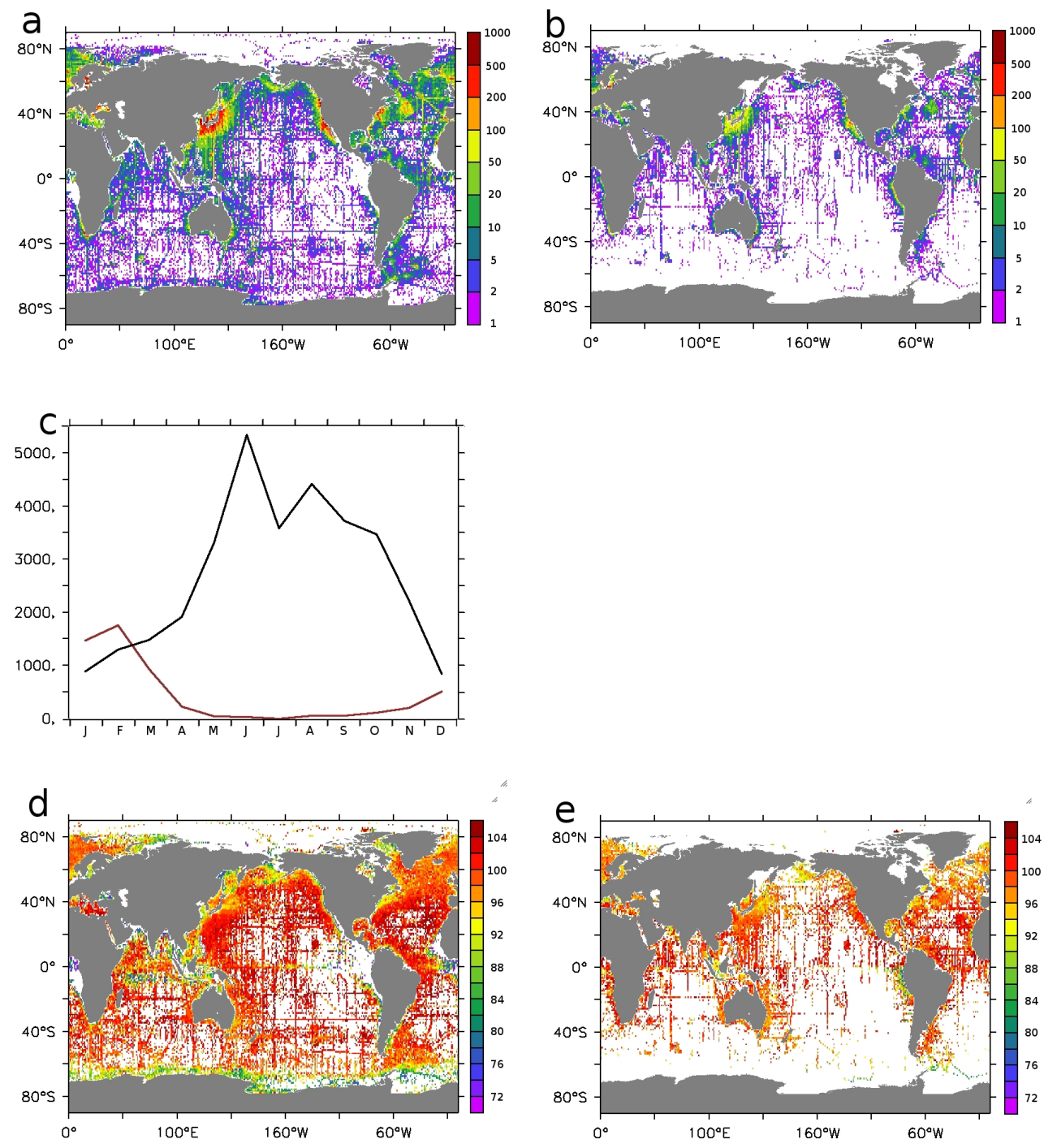

Fig. 5. (a) Surface distribution of observations of oxygen saturation in the World Ocean Dataset (Boyer et al., 2009). Number of observations per $1 \mathrm{x} 1$ grid cell summed over the calendar year and (b) over the corresponding hemisphere winter (Northern Hemisphere : January-FebruaryMarch. Southern hemisphere : July-August-September). (c) Seasonal cycle of the total number of observations in the northern high latitudes (black) $\left(60^{\circ} \mathrm{N}-90^{\circ} \mathrm{N}\right)$ and the Southern Ocean (red) $\left(60^{\circ} \mathrm{S}-90^{\circ} \mathrm{S}\right)$. (d) Percentage of oxygen saturation in the World Ocean Dataset per 1x1 grid cell, averaged over the calendar year (50 m depth) and (e) over the corresponding hemisphere winter (surface) (Northern Hemisphere: JFM. Southern hemisphere: JAS).

gen disequilibria (Fig. 2). On the same isopycnal, waters in, say, the North Atlantic Ocean will mainly stem from northern outcrops of this isopycnal, as will be their preformed oxygen content, while waters in the South Atlantic Ocean will mainly stem from Southern Ocean outcrops. Resolving the complexity of variable water-mass fractions (Gebbie and Huybers, 2011) contributing to the actual preformed oxygen concentration is a non-trivial task. The EOU method is a pragmatic approach to this issue.

The meridional gradient in the relative contributions of different source water masses explains the negative EOUTOU differences in the northern Atlantic Ocean and posi- tive EOU-TOU differences in the Southern Ocean in UVIC and om1p7-BLINGv0. Both models are characterised by large differences in surface oxygen disequilibria between the northern North Atlantic and the Southern Oceans (Fig. 2), the latter being more strongly undersaturated at the $50 \mathrm{~m}$ depth horizon. Considering as we do in the pragmatic EOU approach, globally constant percent fractions of oxygen disequilibrium for any given isopycnal leads to an overestimate of oxygen utilisation in the Southern Ocean and an underestimate of it in the North Atlantic Ocean. Models with smaller differences of surface-ocean oxygen disequilibria in the respective water-mass formation regions also show smaller 
Table 2. Oxygen utilisation $\left(\mathrm{mmolm}^{-3}\right)$ and regenerated over total phosphate ratio $(r /$ tot $)$ computed from AOU, TOU and EOU for different model outputs and WOA dataset.

\begin{tabular}{lccccccc}
\hline $\begin{array}{l}\text { Model or } \\
\text { dataset }\end{array}$ & MOM-P2A & CSIRO & $\begin{array}{c}\text { om1p7- } \\
\text { BLINGv0 }\end{array}$ & UVIC & $\begin{array}{c}\text { TMM- } \\
\text { MIT28 }\end{array}$ & $\begin{array}{c}\text { TMM- } \\
\text { ECCO2 }\end{array}$ & WOA \\
\hline AOU & 142.8 & 147.7 & 186.2 & 156.4 & 141.9 & 164.6 & 153.0 \\
TOU & 121.4 & 129.6 & 120.7 & 119.8 & 130.4 & 140.1 & \\
EOU & 129.5 & 127.0 & 135.3 & 125.2 & 127.9 & 146.0 & 115.5 \\
& & & & & & & \\
$r /$ tot AOU & 0.38 & 0.39 & 0.50 & 0.42 & 0.38 & 0.45 & 0.40 \\
$r /$ tot TOU & 0.32 & 0.34 & 0.32 & 0.32 & 0.34 & 0.37 & \\
$r /$ tot EOU & 0.34 & 0.34 & 0.36 & 0.33 & 0.34 & 0.39 & 0.30 \\
\hline
\end{tabular}

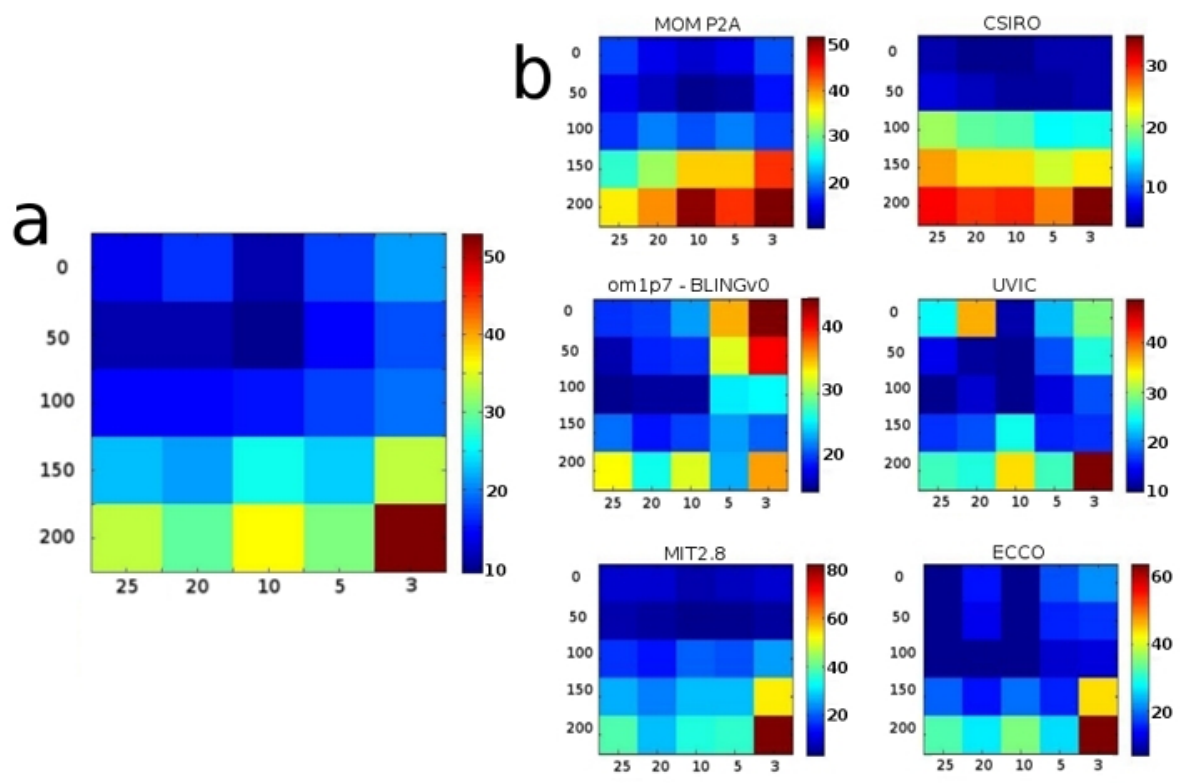

Fig. 6. (a) Model ensemble average of global EOU-TOU rms errors $\left(\mathrm{mmolm}^{-3}\right)$ as a function of the "number of isopycnal layers" (abscissa) and "intercept-depth horizon" (ordinate). The mean of the 6-model ensemble is displayed. The best fit (lowest global rms) is achieved combining 10 isopycnal layers and an intercept-depth of $50 \mathrm{~m}$. (b) Global EOU-TOU rms errors for each model as a function of "number of isopycnal layer" (abscissa) and "intercept-depth horizon" (ordinate). (Please note the differences in scale.)

EOU-TOU differences throughout the ocean. Here the assumption of a mean preformed oxygen concentration for each isopycnal applies much better.

Water masses form mostly in winter. When computing the EOU from models, however, we use annual mean model outputs. This is motivated by our goal to apply the EOU approach to observations in order to better estimate the oxygen utilisation in the global ocean (see Sect. 4). Observations from winter in high latitudes are, however, very scarce. This is particularly true for the Southern Ocean (Fig. 5b and c). Annual data composites, on the other hand, are based on a much larger number of observations (Fig. 5a) and hence less prone to interpolation errors. Using annual means in our model-based method evaluation as well, will provide us with better confidence in the oxygen-utilisation estimate from observational annual composites.

Furthermore, based on the assumption that the upper thermocline is mostly characterised by winter conditions (Stommel, 1979), we can extrapolate surface winter surface fields from these annually averaged observations. We then compute the preformed oxygen used in the EOU method from the mean oxygen disequilibrium of a given isopycnal at a defined depth, rather than at the ocean surface. Testing the sensitivity of the EOU to the depth of this intercept horizon, we find, averaged over all models, that the $50 \mathrm{~m}$ depth horizon leads to the best estimate of the TOU (Fig. 6). The EOU computed in models characterised by a weak seasonal cycle is less sensitive to the value of the intercept-depth horizon 

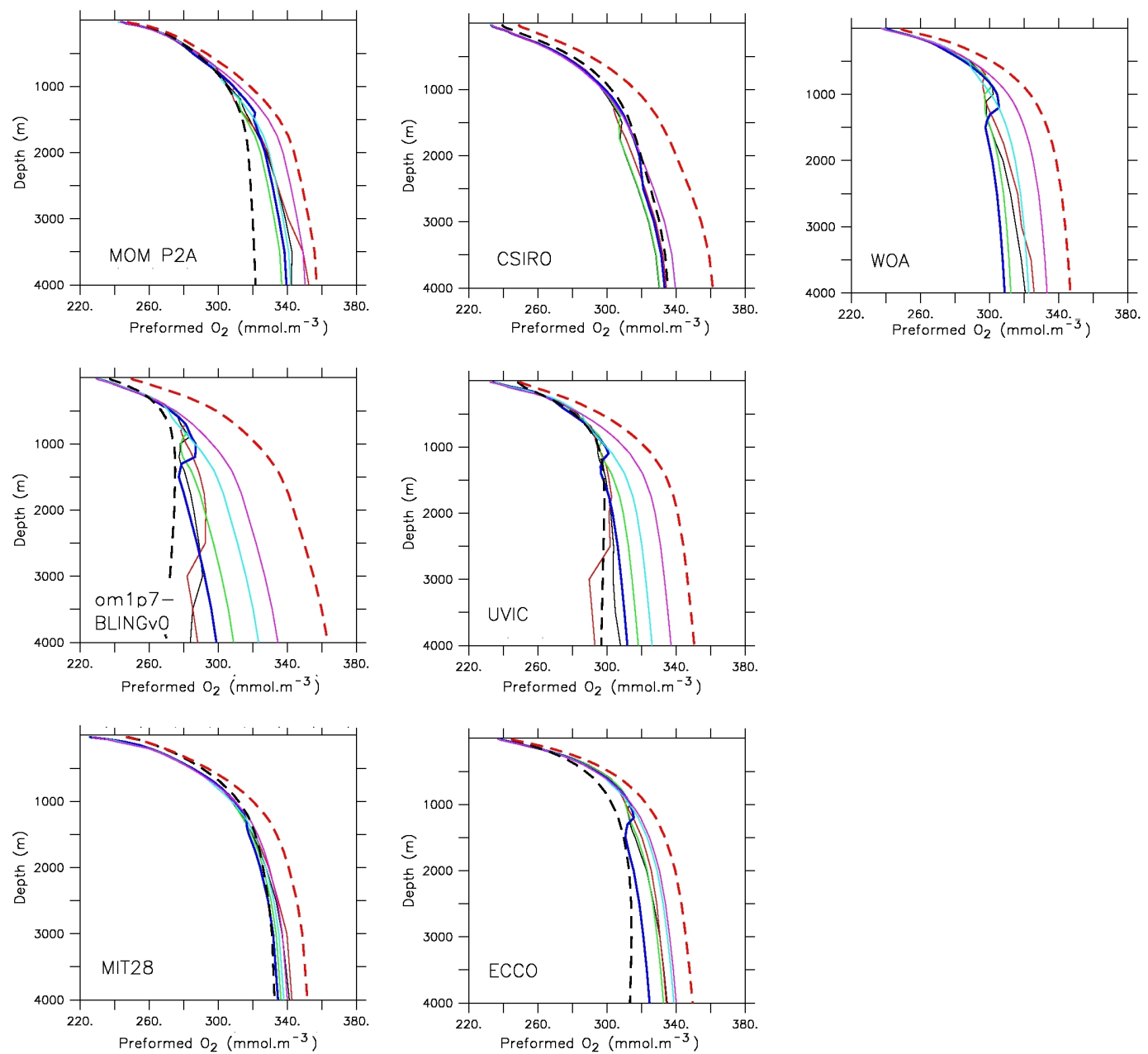

Fig. 7. Global mean profiles of preformed $\mathrm{O}_{2}$ corresponding to TOU (black dashes), AOU (red dashes) and EOU in the different models: CSIRO, MOM-P2A, om1p7-BLINGv0, UVIC, TMM-MIT28, TMM-ECCO2, and in the WOA. EOU has been computed considering an increasing number of density layers ranging from 3-25 (black: 25 layers; red: 20; green: 15; blue: 10; light blue: 5; magenta: 3).

than the EOU computed in models where the seasonal cycle is strong, especially at high latitudes.

Another critical parameter of the EOU method is the degree of vertical discretization, i.e. the number of isopycnal layers. The main factor explaining the sensitivity to the number of isopycnal layers is the heterogeneity of oxygen disequilibrium in the near-surface waters. A model ocean that displays a spatially invariable surface oxygen disequilibrium will not be very sensitive to the degree of vertical discretization in isopycnal layers. This is the case in, for instance, MIT28 or CSIRO (Fig. 7). Conversely, UVIC or om1p7-BLINGv0, characterised by a stronger heterogeneity of surface ocean oxygen disequilibria (Fig. 2) display a large sensitivity to the number of isopycnal layers. The 'optimal' number of layers to take into account in computing EOU also depends on the strength of diapycnal mixing. A model characterised by very high diapycnal diffusivity in the interior ocean will not conserve the outcrop properties in the ocean interior and the EOU-TOU bias will be minimised when only few isopycnal layers are considered. Conversely, a model characterised by weak diapycnal diffusivity requires a higher number of isopycnal layers in order to reproduce the ocean interior correctly. Using an ensemble average, we find that dividing the ocean into 10 isopycnal layers of equal density width $\left(1 \mathrm{~kg} \mathrm{~m}^{-3}\right)$ between 1020.5 and $1030.5 \mathrm{~kg} \mathrm{~m}^{-3}$ leads to the best estimate of the TOU (Figs. 6 and 7). This is the number of layers we apply in this study, both in the models and the observations (Sect. 4). A good agreement is however generally found between EOU and TOU for a depth horizon ranging from $0-100 \mathrm{~m}$ and a number of 5-25 isopycnal layers, allowing us to test the robustness of the EOU and determine some confidence in its value when applied to observations 

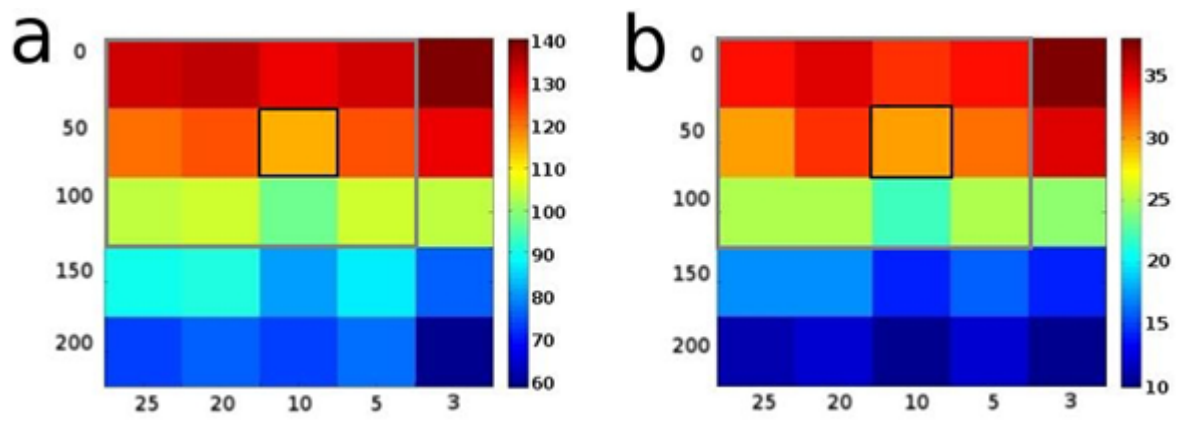

Fig. 8. (a) Mean EOU in the world ocean $\left(\mathrm{mmolm}^{-3}\right)$ as a function of the number of isopycnal layers (abscissa) and intercept-depth horizon (ordinate).(b) Mean ratio of regenerated over total phosphates $\left(R_{\mathrm{P}:-\mathrm{O}_{2}}=1 / 170\right)$ in the world ocean $\left(\mathrm{mmol} \mathrm{m}^{-3}\right)$ as a function of the number of isopycnal layers (abscissa) and intercept depth horizon (ordinate). Using $50 \mathrm{~m}$ as a depth horizon and 10 isopycnal layer gives the best approximation of the true oxygen utilisation (black), while using a depth horizon range of $0-100 \mathrm{~m}$ and 5 to 25 isopycnal layers still gives a good approximation (gray) (see Fig. 6)

\section{Application of the EOU concept to observations}

Encouraged by the improvements the EOU method gave for oxygen utilisation in the model simulations, we now apply it to a climatological observational database, the World Ocean Atlas 2009 (WOA) (Fig. 9a). In the deep ocean, between 2000 and $4000 \mathrm{~m}$ depth, EOU is about $30-40 \mathrm{mmol} \mathrm{m}^{-3}$ less than AOU, which corresponds to about a $25 \%$ reduction compared to the mean AOU value. In intermediate waters, between 500 and $1500 \mathrm{~m}$ depth, the difference between AOU and EOU reaches $10-20 \mathrm{mmol} \mathrm{m}^{-3}$ in the tropical Ocean and $40 \mathrm{mmolm}^{-3}$ in the Southern Ocean (Fig. 9b). The global mean AOU is $153 \mathrm{mmol} \mathrm{m}^{-3}$ whereas the global mean EOU is only $115.5 \mathrm{mmol} \mathrm{m}^{-3}$ (Table 2).

Can we trust this value? Unlike in the models, where we can "ground truth" the EOU estimates using the preformedoxygen tracer, this is not possible in the real ocean. However, applying the discussion of the EOU uncertainty in models (Sect. 3.5), we attempt to estimate the uncertainty of EOU in observations.

The largest surface-ocean oxygen disequilibrium occurs in high-latitude subduction regions, where deep water (here considered as the water of potential density greater than $1027.5 \mathrm{~kg} \mathrm{~m}^{-3}$ ) forms. This deep water is subducted both in the Southern Ocean (forming the AABW) and in the northern North Atlantic (forming NADW). The annual mean oxygen field at $50 \mathrm{~m}$ depth (corresponding to the depth used to compute the preformed oxygen in the EOU approach) of the dense Southern Ocean waters has a mean saturation of $86 \%$ (Fig. 5d and e), with a mean oxygen concentration of $324 \mathrm{mmolm}^{-3}$. The greatest undersaturation occurs in the Ross and Weddell Seas (Gordon and Huber, 1990; Keeling et al., 2010), which are both important sites of deepwater formation. In the northern North Atlantic, the annual mean oxygen saturation at $50 \mathrm{~m}$ depth is $96 \%$, with a mean oxygen concentration of $300 \mathrm{mmolm}^{-3}$. Deep winter convection at the sites of NADW formation usually carries rel- atively young waters with little oxygen consumption back to the surface. Analysing in-situ data clearly shows that the oxygen disequilibrium is not just a model artefact, but also an observed feature.

The water masses making up the deep ocean have inherited different surface oxygen disequilibrium values and are mixed in different proportions. In the EOU method, however, we use disequilibrium values which only vary with density and we hence do not take into account the regional distribution of these disequilibria, nor the meridional variability of the water mass contribution on a given isopycnal.

In the observations, about $36 \%$ of the outcrop area of dense (density $>1027.5 \mathrm{~kg} \mathrm{~m}^{-3}$ ) water is located in the North Atlantic, and 64 percent in the Southern Ocean (Weddell and Ross Seas). In our EOU approach, this implies that the dense water is assumed to consist of about one third of NADW and two thirds of AABW, which is comparable to the results of Johnson (2008) and Khatiwala et al. (2012). The mean evaluated preformed oxygen in the deep ocean is $309 \mathrm{mmol} \mathrm{m}^{-3}$. Considering a hypothetical mixing of $50 \% \mathrm{AABW}$ and $50 \%$ NADW would lead to a larger value of about $315 \mathrm{mmol} \mathrm{m}^{-3}$. As a note of caution, estimates of source-water mass fractions are sensitive to the choice of the water mass end members and the methods and tracers applied (Broecker et al., 1998; Johnson, 2008; Gebbie and Huybers, 2011), hence our pragmatic approach to assess the preformed oxygen.

Dense waters observed in the North Atlantic mainly stem from the northern outcrop, as does their oxygen disequilibrium, while waters in the South Atlantic mainly stem from the Southern Ocean outcrops. As shown by Khatiwala et al. (2012), nearly 80 percent of the deep water of the Southern Ocean has been formed locally. Considering a mixture 20 (80) \% of AABW and 80 (20) \% of NADW leads to a mean preformed oxygen concentration of $325(305) \mathrm{mmolm}^{-3}$. In our approach, this meridional gradient is not correctly taken into account, leading to regionally varying errors with maxi- 

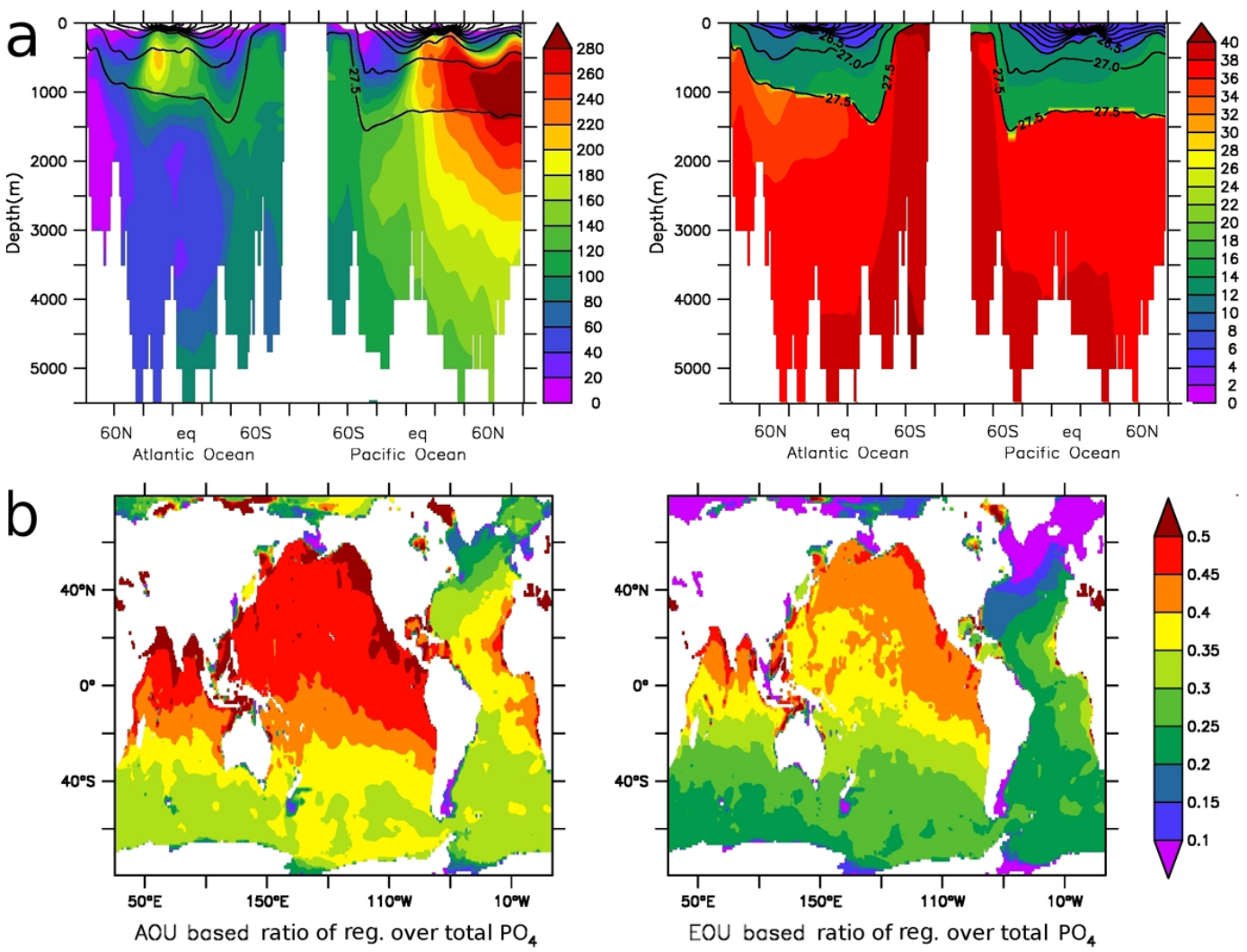

Fig. 9. (a) Evaluated Oxygen Utilisation (EOU) (left) and AOU-EOU (right) (mmol ${ }^{-3}$ ) along an Atlantic meridional section $\left(30^{\circ}\right.$ W) and Pacific meridional section $\left(150^{\circ} \mathrm{W}\right)$ in WOA. (b) Averaged water column ratio of regenerated over total phosphate concentration computed using AOU (left) and EOU (right) $\left(R_{\mathrm{P}:-\mathrm{O}_{2}}=1 / 170\right)$.

mum values of $\pm 15 \mathrm{mmol} \mathrm{m}^{-3}$ close to the outcrop regions. Near the outcrop of AABW, a 64:36 mixture of AABW to NADW (preformed concentration of $309 \mathrm{mmolm}^{-3}$, as described in the paragraph above) would overestimate the preformed oxygen by about $5 \mathrm{mmolm}^{-3}$ compared to a 80 : 20 mixture (preformed concentration of $305 \mathrm{mmolm}^{-3}$ ). Inversely, near the outcrop of NADW, a $64: 36$ mixture of AABW to NADW would underestimate the preformed oxygen by $15 \mathrm{mmolm}^{-3}$ compared to a $20: 80$ mixture (preformed concentration of $325 \mathrm{mmolm}^{-3}$ ).

We computed the preformed oxygen used for EOU from the mean oxygen disequilibrium of a given isopycnal at the intercept with the $50 \mathrm{~m}$ depth layer rather than the ocean surface. The choice of this depth horizon is pragmatic and guided by the model sensitivity analyses discussed in Sect. 3.5 (Fig. 6). Choosing a shallower (deeper) depth horizon would result in a higher (lower) oxygen saturation and ultimately preformed oxygen concentration, as shown in Table 3. Using surface values would still lead to an undersaturation in deep water by about $25 \mathrm{mmol} \mathrm{m}^{-3}$, whereas considering $50 \mathrm{~m}$ as the intercept depth-horizon leads to an undersaturation of $35 \mathrm{mmolm}^{-3}$. When $100 \mathrm{~m}$ depth is used as the intercept depth, the undersaturation amounts to about $60 \mathrm{mmol} \mathrm{m}^{-3}$ in the densest water class.

Another support for our choice of the $50 \mathrm{~m}$ depth horizon comes from a consideration of phosphate concentrations: following Broecker et al. (1985), the concentration of phosphate in the NADW end member is $0.73 \mathrm{mmolm}^{-3}$ whereas it is $1.95 \mathrm{mmolm}^{-3}$ in the AABW. The mean phosphate concentration in the dense water at $50 \mathrm{~m}$ depth in the Southern Ocean and $100 \mathrm{~m}$ in the North Atlantic Ocean well agrees with these values (Table 3), suggesting these depth layers to be characteristic of the outcrops in winter when water subducts. If we had used a different depth horizon in the Southern Ocean $(50 \mathrm{~m})$ and in the North Atlantic Ocean $(100 \mathrm{~m})$, the estimated preformed oxygen of the densest water class would be lower by $10 \mathrm{mmolm}^{-3}$.

In the observations, the preformed oxygen concentration of $309 \mathrm{mmolm}^{-3}$ is computed for the deep ocean (density $>1027.5 \mathrm{~kg} \mathrm{~m}^{-3}$ ) when 10 isopycnal layers are considered (Fig. 7), which is the number of layers leading to the optimal fit of EOU-TOU in the models we considered (see Sect. 3.5). The maximum value is $320 \mathrm{mmolm}^{-3}$ when 5 layers are considered, corresponding to the minimum number of layers needed to discriminate the main water masses, 
which is significantly lower than the value of $345 \mathrm{mmolm}^{-3}$ derived from TS (AOU methodology). Increasing the number of layers beyond 10 does not significantly modify the preformed oxygen concentration. Hence, this suggests that the mean preformed concentration is likely between 309 and $320 \mathrm{mmolm}^{-3}$ in the deep ocean layer.

Finally, the oxygen utilisation values obtained by the different EOU computations are summarised in the Fig. 8a, which highlights the impact of the isopycnal discretization and the choice in the depth horizon. The mean EOU is $115 \mathrm{mmol} \mathrm{m}^{-3}$ when 10 isopycnal levels and a depth horizon of $50 \mathrm{~m}$ are used for its computation. Using the surface as depth horizon increases this value by about $15 \mathrm{mmolm}^{-3}$, while considering a deeper depth horizon of $100 \mathrm{~m}$ decreases this value by about $15 \mathrm{mmolm}^{-3}$. Computing the EOU for depth horizons greater than $100 \mathrm{~m}$ leads to an inaccurate evaluation of the true oxygen utilisation, as shown by the Fig. 6 a. Similar values $( \pm 15 \%)$ are found when the number of isopycnal varies from 5-25, which are the number of levels where the agreement between the TOU and the EOU are the greatest in the models (Fig. 6a)

Given that the EOU in all six models still overestimate oxygen utilisation (Figs. 4 and 7), we speculate that EOU overestimates oxygen utilisation in the real ocean too, but to a much smaller degree than AOU.

\section{Preformed and regenerated phosphates}

The revised estimation of oxygen utilisation in the ocean leads to a reassessment of the fraction of regenerated nutrients to the total nutrient pools in the ocean's interior. In this conceptual approach of Ito and Follows (2005) regenerated nutrients are the nutrients which returned to the interior of the ocean via particle export from the surface ocean or as dissolved organic matter (and subsequent remineralization in the interior), whereas preformed nutrients are transported in inorganic form from the surface to the interior by subduction and the thermohaline circulation.

Regenerated phosphate is usually computed by multiplying Oxygen Utilisation (AOU or EOU) with the oxidation ratio $R_{\mathrm{P}:-\mathrm{O}_{2}}$. The ratio of $1 / 170$ has been derived from in-situ water column observations and is commonly used (Takahashi et al., 1985; Anderson and Sarmiento, 1994; Li et al., 2000; Körtzinger et al., 2001). However, a smaller ratio of $1 / 150$ $( \pm 10)$ has been estimated by Anderson (1995) in algal cells, assuming on average a $C: N: P$ ratio of $106: 16: 1$.

The global mean regenerated/total ratio for phosphate, derived from WOA observations and using AOU diagnostic, ranges from $0.40\left(R_{\mathrm{P}:-\mathrm{O}_{2}}=1 / 170\right)$ to $0.47\left(R_{\mathrm{P}:-\mathrm{O}_{2}}=\right.$ $1 / 150)$. Using a data-constrained ocean circulation and biogeochemistry model and basing their estimate on nutrient export and sequestration since the last contact of a given water parcel with the atmosphere, DeVries et al. (2012) proposed a higher value of 0.50. In this study, using the EOU approach, we show that the regenerated/total ratio appears to be significantly lower than either prior estimate with a global mean value ranging from $0.30\left(R_{\mathrm{P}:-\mathrm{O}_{2}}=1 / 170\right)$ (Fig. $9 \mathrm{~b}$ and Table 3$)$ to $0.35\left(R_{\mathrm{P}:-\mathrm{O}_{2}}=1 / 150\right)$.

The uncertainties in EOU (see Sect. 4) lead to an uncertainty $\pm 15 \%$ of this value (see Fig. 8 b). The regenerated/total ratio for phosphate is 30 percent smaller than when determined using the AOU approach in the Southern Ocean (south of $50^{\circ} \mathrm{S}$ ).

This result may not be easily generalized to the carbon cycle: the ocean-atmosphere equilibration time for $\mathrm{CO}_{2}$ is one order of magnitude larger than with oxygen, and surface disequilibria will have a different and potentially more complex effect on carbon storage.

\section{Conclusions}

The concentration of oxygen in the ocean's interior results from the interaction of circulation dynamics, respiration and air-sea exchanges. In a comparison of six global models, we confirmed that AOU is a biased estimate of effective respiration (TOU) due to disequilibrium between the surface ocean and atmosphere. The EOU approach consists of estimating the preformed oxygen concentration of a given isopycnal layer by the near-surface disequilibrium in regions where the isopycnal layer crops out. This approach performs better then AOU in estimating TOU. Thus, we recommend to use the EOU approach in studies where an accurate estimate of respiration is important. For instance, the EOU approach could be used in combination with an estimate of water mass ventilation rate in order to infer rates of oxygen consumption in the ocean's interior.

With our new global EOU estimate being about 25 percent lower than the classical AOU estimate, our results suggest that oxygen consumption rates in the ocean interior may be considerably lower than estimated previously.

Acknowledgements. Comments by Paul Kähler are appreciated. We acknowledge financial support to O. Duteil, A. Oschlies and I. Kriest from the Deutsche Forschungsgemeinschaft (SFB 754), to W. Koeve from the German Federal Ministry of Education and Research (FKZ 03F0608A, BIOACID), to R. Matear from the funding support of the Australian Climate Change Science Programme. The research of D. Bianchi was funded by Canadian Institute for Advanced Research (CIFAR) Earth System Evolution program. The research of E. Galbraith was funded by the Natural Sciences and Engineering Research Council (NSERC), the Canadian Institute for Advanced Research (CIFAR) and Compute Canada.

The service charges for this open access publication have been covered by a Research Centre of the Helmholtz Association.

Edited by: F. Joos 


\section{References}

Anderson, L. A.: On the hydrogen and oxygen content of marine phytoplankton, Deep-Sea Res. I, 42, 1675-1680, 1995.

Anderson, L. A. and Sarmiento, J. L.: Redfield ratios of remineralization determined by nutrient data analysis, Global Biogeochem. Cy., 8, 65-80, 1994.

Anderson, L. A. and Sarmiento, J. L.: Global ocean phosphate and oxygen simulations, Global Biogeochem. Cy., 9, 621-636, 1995.

Aristegui, J., Duarte, C. M., Agusti, S., Doval, M. D., AlvarezSalgado, X. A., and Hansell, D. A.: Dissolved organic carbon support of respiration in the dark ocean, Science, 298, 1967, doi:10.1126/science.1076746, 2002.

Broecker, W. S., Takahashi, T., and Takahashi, T.: Sources and flow patterns of deep ocean waters as deduced from potential temperature, salinity, and initial phosphate concentration, J. Geophys. Res. Oc., 90, 6925-6939, 1985.

Boyer, T. P., Antonov, J. I., Baranova, O. K., Garcia, H. E., Johnson, D. R., Locarnini, R. A., Mishonov, A. V., O’Brien, T. D., Seidov, D., Smolyar, I. V., and Zweng, M. M.: World Ocean Database 2009, edited by: Levitus, S., NOAA Atlas NESDIS 66, US Gov. Printing Office, Washington, DC, 216 pp., DVDs, 2009.

Broecker, W. S., Peacock, S. L., Walker, S., Weiss, R., Fahrbach, E., Schroeder, M., Mikolajewicz, U., Heinze, C., Key, R., Peng, T. H., and Rubin, S.: How much deep water is formed in the Southern Ocean?, J. Geophys. Res., 103, 15833-15843, 1998.

Carlson, C. A., Hansell, D. A., Nelson, N. B., Siegel, D. A., Smethie, W. M. J., Khatiwala, S., Meyers, M. M., and Halewood, E.: Dissolved organic carbon export and subsequent remineralization in the mesopelagic and bathypelagic realms of the North Atlantic basin, Deep-Sea Res. II, 57, 1433-1445, 2010.

Craig, H. and Hayward, T. L. : Oxygen supersaturation in the ocean: biological versus physical contributions, Science, 235, 199-206, 1986.

DeVries, T., Primeau, F., and Deutsch, C.: The sequestration efficiency of the biological pump, Geophys. Res. Lett., 39, L13601, doi:10.1029/2012GL051963, 2012.

Dietze, H. and Oschlies, A.: Modeling abiotic production of apparent oxygen utilisation in the oligotrophic subtropical North Atlantic, Oc. Dynam., 55, 28-33, 2005.

Doval, M. D. and Hansell, D. A.: Organic carbon and apparent oxygen utilization in the western South Pacific and the central Indian Oceans, Mar. Chem., 68, 249-264, doi:10.1016/S03044203(99)00081-X, 2000.

Duteil, O., Koeve, W., Oschlies, A., Aumont, O., Bianchi, D., Bopp, L., Galbraith, E., Matear, R., Moore, J. K., Sarmiento, J. L., and Segschneider, J.: Preformed and regenerated phosphate in ocean general circulation models: can right total concentrations be wrong?, Biogeosciences, 9, 1797-1807, doi:10.5194/bg-9-1797-2012, 2012.

Emerson, S., Watanabe, Y. W., Ono, T., and Mecking S.: Temporal trends in apparent oxygen utilisation in the upper pycnocline of the North Pacific: 1980-2000, J. Oceanogr., 60, 139-147, 2004.

Feely, R., Sabine, C., Lee, K., Berelson, W., Kleypas, J., Fabry, V., and Millero, F.: Impact of anthropogenic $\mathrm{CO}_{2}$ on the $\mathrm{CaCO}_{3}$ system in the oceans, Science, 305, 362-371, 2004.

Galbraith, E. D., Gnanadesikan, A., Dunne, J. P., and Hiscock, M. R.: Regional impacts of iron-light colimitation in a global biogeochemical model, Biogeosciences, 7, 1043-1064, doi:10.5194/bg-7-1043-2010, 2010.
Garcia, H. E., Locarnini, R. A., Boyer, T. P., Antonov, J. I., Baranova, O. K., Zweng, M. M., and Johnson, D. R.: World Ocean Atlas 2009, vol. 3: Dissolved Oxygen, Apparent Oxygen Utilisation, and Oxygen Saturation, edited by: Levitus, S., NOAA Atlas NESDIS 70, US Government Printing Office, Washington, DC, 344 pp., 2010.

Gebbie, G. and Huybers, P.: How is the ocean filled?, Geophys. Res. Lett., 38, L06604, doi:10.1029/2011GL046769, 2011.

Gnanadesikan, A.: A simple model for the structure of the oceanic pycnocline, Science, 283, 2077-2079, 1999.

Gnanadesikan, A., Dunne, J., Key, R., Matsumoto, K., Sarmiento, J., Slater, R., and Swathi, P.: Oceanic ventilation and biogeochemical cycling: understanding the physical mechanisms that produce realistic distributions of tracers and productivity, Global Biogeochem. Cy., 18, GB4010, doi:10.1029/2003GB002097, 2004.

Gordon, A. and Huber, B.: Southern ocean mixed layer, J. Geophys. Res.-Oceans, 95, 11655-11672, 1990.

Ito, T. and Follows, M.: Preformed phosphate, soft tissue pump and atmospheric $\mathrm{CO}_{2}$, J. Mar. Res., 63, 813-839, 2005.

Ito, T., Follows, M., and Boyle, E.: Is AOU a good measure of respiration in the oceans?, Geophys. Res. Lett., 31, L17305, doi:10.1029/2004GL020900, 2004.

Johnson, G. C.: Quantifying Antarctic Bottom Water and North Atlantic Deep Water volumes, J. Geophys. Res., 113, C05027, doi:10.1029/2007JV004477, 2008.

Keeling, R. F., Koertzinger, A., and Gruber, N.: Ocean deoxygenation in a warming world, Annu. Rev. Mar. Sci., 2, 199-229, doi:10.1146/annurev.marine.010908.163855, 2010.

Koeve, W.: Wintertime nutrients in the North Atlantic - new approaches and implications for estimates of seasonal new production, Mar. Chem., 74, 245-260, 2001.

Körtzinger, A., Hedges, J., and Quay, P.: Redfield ratios revisited: Removing the biasing effect of anthropogenic $\mathrm{CO}_{2}$, Limnol. Oceanogr., 46, 964-970, 2001.

Körtzinger, A., Schimanski, J., Send, U., and Wallace, D. W. R.: The ocean takes a deep breath Science, 306, 5700, doi:10.1126/science.1102557, 2004

Khatiwala, S.: A computational framework for simulation of biogeochemical tracers in the ocean, Global Biogeochem. Cy., 21, GB3001, doi:10.1029/2007GB002923, 2007.

Khatiwala, S., Primeau, F., and Holzer, M.: ventilation of the deep ocean constrained with tracer observations and implications for radiocarbon estimates of ideal mean age. Earth and Planet. Sci. Lett., 325/326, 116-125, doi:10.1016/j.eps1.2012.01.038, 2012.

Kriest, I., Khatiwala, K., and Oschlies, A.: Assessment of simple global marine biogeochemical models of increasing complexity, Prog. Oceanogr., 86, 336-360, 2010.

Li, Y. H., Karl, D. M., Winn, C. D., Mackenzie, F. T., and Gans, K.: Remineralization ratios in the subtropical north Pacific gyre, Aquatic Geochem., 6, 65-86, 2000.

Matear, R. and Hirst, A.: Long-term changes in dissolved oxygen concentrations in the ocean caused by protracted global warming, Global Biogeochem. Cy., 17, GB4008, doi:10.1029/2002GB001997, 2003.

Najjar, R.: Marine Biogeochemistry, in: Climate System Modeling, edited by: Trenberth, K., Cambridge University Press, Cambridge, England, 241-280, 1992. 
Nevison, C., Butler, J. H., and Elkins, J. W.: Global distribution of $\mathrm{N}_{2} \mathrm{O}$ and the Delta $\mathrm{N}_{2} \mathrm{O}-\mathrm{AOU}$ yield in the subsurface ocean. Global Biogeochemical Cycles, 17, 1119, doi:10.1029/2003GB002068, 2003.

Ogura, N.: The relation between dissolved organic carbon and apparent oxygen utilisation in the Western North Pacific, Deep-Sea Res., 17, 221-231, 1970.

Oschlies, A., Schulz K., Riebesell U., and Schmittner, A.: Simulated 21 st century's increase in oceanic suboxia by $\mathrm{CO}_{2}$-enhanced biotic carbon export, Global Biogeochem. Cy., 22, GB1125, doi:10.1029/2007GB003147, 2008.

Pahlow, M. and Riebesell, U.: Temporal trends in deep ocean Redfield ratios, Science, 287, 831-832, 2000.

Redfield, A. C., Ketchum, B. H., and Richards, F. A.: The influence of organisms on the composition of seawater, in: The Sea, vol. 2, edited by: Hill, M. N., John Wiley and Sons, New York, 26-77, 1963.

Russell, J. L. and Dickson, A. G.: Variability in oxygen and nutrients in South Pacific Antarctic Intermediate Water, Global Biogeochem. Cy., 17, 1033, doi:10.1029/2000GB001317, 2003.
Sarmiento, J. L. and Gruber, N.: Ocean Biogeochemical Dynamics, Princeton University Press, Princeton, NJ, 526 pp., 2006.

Sarmiento, J. L., Thiele, G., Key, R. M., and Moore, W. S.: Oxygen and nitrate new production and remineralizaion in the North Atlantic subtropical gyre, J. Geophys. Res., 95, 18,303-18,315, 1990.

Stammer, D., Ueyoshi, K., Kohl, A., Large, W. G., Josey, S. A., and Wunsch, C.: Estimating air-sea fluxes of heat, freshwater, and momentum through global ocean data assimilation, J. Geophys. Res., 109, C05023, doi:10.1029/2003JC002082, 2004.

Stommel, H.: Determination of water mass properties of water pumped down from the Ekman layer to the geostrophic flow below, P. Natl. Acad. Sci. USA, 76, 3051-3055, 1979.

Takahashi, T., Broecker, W. S., and Langer, S.: Redfield ratio based on chemical data from isopycnal surfaces, J. Geophys. Res.Oceans, C4, 6907-6924., 1985.

Weiss, R.: The solubility of nitrogen, oxygen, and argon in water and seawater, Deep-Sea Res., 17, 721-756, 1970. 